\title{
Better home care and better pay for doctors urged at CMA town hall
}

$\mathrm{E}$ ven on a cold winter night, it seems Canadians can't resist the promise of an earnest evening of debate over medicare reform: With 500 people in the room and another 150 turned away on Mar. 1 in Toronto, Ontario, at the Canadian Medical Association's second town hall meeting on health care transformation, it's evident that a passion for public health persists in Canada's biggest city.

In a two-hour session structured to allow ample commentary from a crowd heavily stocked with health professionals, CMA President Dr. Jeff Turnbull and a panel including Ontario Medical Association President Dr. Mark MacLeod contended with a barrage of calls for sweeping reforms to sizeable portions of Canada's universal access health care system.

The aim of the exercise, according to Turnbull, was to get "everyone around the table" and encourage a little public dialogue - but no ranting, please - on central issues such as the role of the federal government in health care, and how the Canada Health Act might be refashioned.

Both issues elicited forceful discussion (and just a few rants) about the need to expand public health to include pharmacare and homecare, and the need to shift the current focus from acute care toward chronic care.

Secondary themes included the need to develop greater transparency and accountability in health care, and the need to invest in electronic information technologies.

"Too many seniors are slipping through the cracks. They inevitably wind up in emergency wards," warned Toronto physician Dr. Mark Nowaczynski. "Why isn't home health care in the Canada Health Act?"

A major reason patients are not treated in their homes, Nowaczynski explained, is that under current pay schemes, care providers wind up receiving around $40 \%$

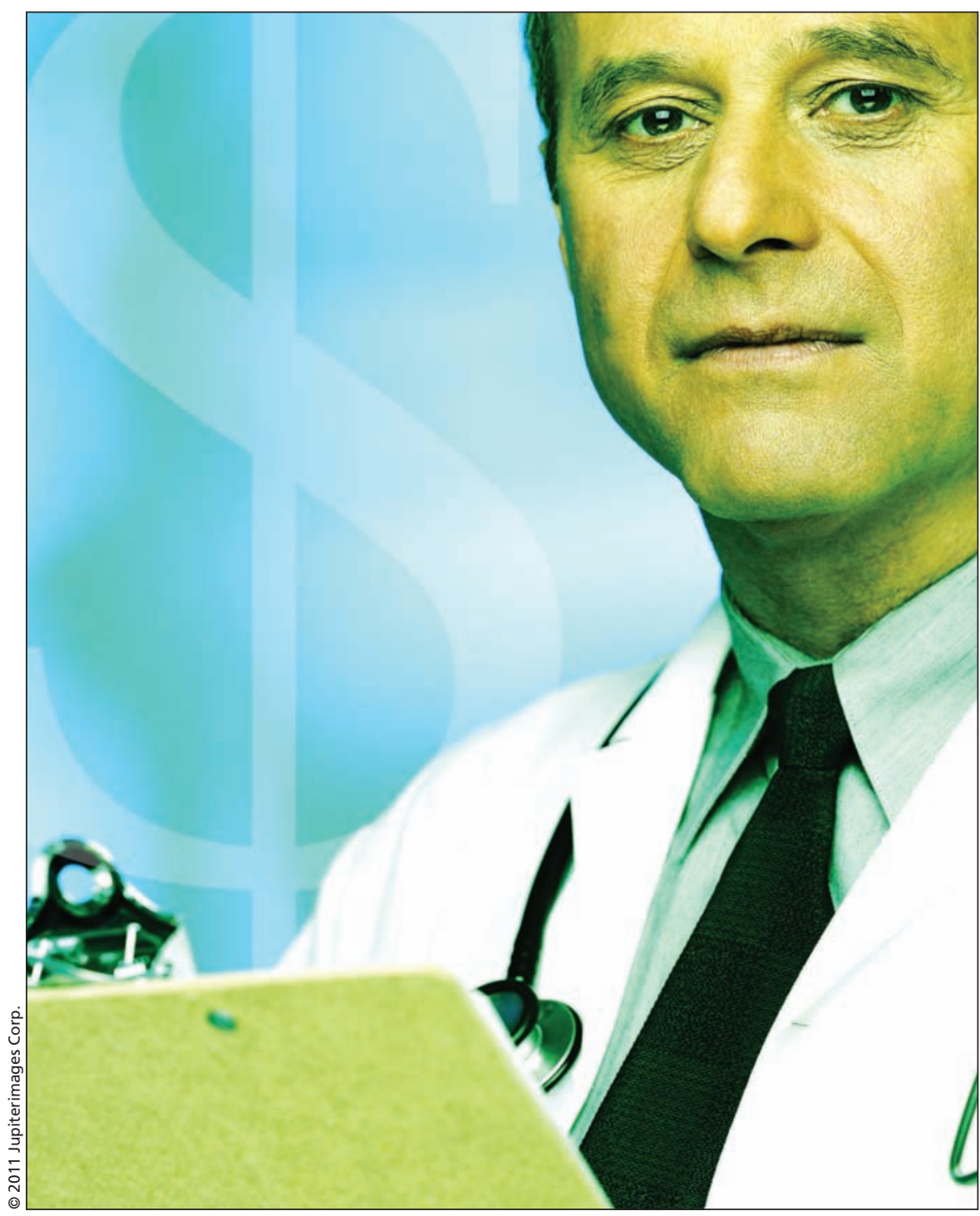

Payment models for doctors providing home care was among the most topical issues raised at the Canadian Medical Association's second town hall meeting on health care transformation.

less pay for the extra time and effort required to get out of their offices and into patients' homes.

"We need to make a business case for doing home care," Nowaczynski urged. "It's just too hard to sell interns and doctors on a pay cut."

MacLeod concurred, noting that up to $20 \%$ of Ontario hospital beds "are occupied by people who could be treated at home or in other institutions." In order to encourage doctors to treat people at home, governments will have to reform payment models, he argued.

The home care quandary, many participants noted, reflects demographic patterns in which increasing numbers of aging patients now require escalating levels of costly care.

"The system has not changed but the 
population has," suggested Dr. Samir Sinha, director of geriatrics at Mount Sinai Hospital in Toronto.

Meanwhile, there are only about 200 geriatricians practising in Canada, about one-quarter the statistically appropriate number, Sinha said. Here again, pay structures serve as disincentives for physicians working with the elderly, he complained.

But anxieties over the costs of caring for an aging population - described as "eating us alive" by panelist Andrew Coyne, national editor of Maclean's may be overstated, argued Derek Chadwick, a board member of the Ontario Health Coalition.

Chadwick suggested that various analyses indicate that care for the elderly will prove less costly than predicted. The real fiscal menace is the cost of drugs, he said, adding that a publicly managed and funded pharmacare system "would, in fact, save a lot of money."

Canadian Doctors for Medicare Chair and Toronto family physician Dr. Danielle Martin also argued that a single payer pharmacare system would achieve cost control over rapidly increasing pharmaceutical costs in Canada. "If there is any one Pac-Man eating up health care budgets, it's pharma," she quipped. "From a purely economic perspective, we need pharmacare."

Among the four panelists, only Durhane Wong-Reiger, president of the Institute for Optimizing Health Outcomes, spoke in support of pharmacare. She cast the lack of public pharmacare, which leaves many patients unable to afford medicines provided for free when they are in hospital, as a "gaping hole" in the system.

But Mary Jo Haddad, president and CEO of Toronto's Hospital for Sick Children argued that a national pharmacare plan shouldn't be on the table. "We can't afford to add and add" to medicare.

MacLeod said efficiencies in the current system should be pursued before adding new elements. "If we are going to add things we are going to have to be fully informed about their costs."

More starkly, Coyne argued that national pharmacare would create "an open-ended financial obligation" at a time when Canada's "unfunded liabilities" for social programs are already as high as \$1.8-trillion.

Coyne added that as much $30 \%$ of current health care costs could be slashed through "efficiency gain," but did not specify areas. MacLeod noted that there are benefits to be found through greater investments in electronic health information technologies.

That drew strong support from Barrie, Ont. anesthesiologist Dr. Doug Crawford, who complained that, while federal and provincial governments have spent billions on misdirected electronic health information investments, "they haven't asked us what we want."

The town hall meetings are part of a broad public consultation that CMA launched in 2010 to spark an "adult conversation" on updating and expanding the Canada Health Act (www.cmaj .ca/cgi/doi/10.1503/cmaj.109-3333). At the first meeting in Halifax, Nova Scotia, delegates focused on systemic problems such as lengthy wait times, "gross inequities" in access to treatment and waste within the system (www.cmaj.ca/cgi/doi/10.1503/cmaj .109-3797). The conversation will continue with town halls in Edmonton, Alberta and Vancouver, British Columbia before wrapping up with one in Ottawa, Ontario. - Paul Christopher Webster, Toronto, Ont.

CMAJ 2011. DOI:10.1503/cmaj.109-3831 